\title{
Thermal Studies of Terephthalate Copolyesters ${ }^{\dagger}$
}

\author{
E. PONNUSAMY* and T. BALAKRISHNAN \\ Department of Physical Chemistry, University of Madras, \\ Guindy Campus, Madras 600025, India
}

(Received December 24, 1986)

\begin{abstract}
Differential thermal analysis of random terephthalate copolyesters of ethylene glycol and butane-1,4-diol showed that the thermal properties $\left(T_{\mathrm{m}}, T_{\mathrm{c}}, \Delta H_{\mathrm{f}}, \Delta S_{\mathrm{f}}\right.$, and $\left.X_{\mathrm{c}}\right)$ follow an independent curve with comonomer composition. The kinetics of thermal degradation of these copolyesters were studied by thermogravimetry and the major degradation mechanism was found to be unimolecular.
\end{abstract}

KEY WORDS Copolyesters / Differential Thermal Analysis / Enthalpy of Fusion / Entropy of Fusion / Thermogravimetry / Kinetic Order / Activation Energy /

Thermoanalytical methods, such as differential thermal analysis (DTA), thermogravimetry (TG) and thermovolumetry have been employed increasingly in the investigation of chemical ralations in the liquid and solid states at elevated temperatures. These techniques involves the continuous measurement of a change in physical property, such as weight, volume, heat capacity etc., as sample temperature is increased, usually at a programmed rate of heating. DTA studies provide structural information on comonomer distribution, tacticity and crystallinity of the copolymers. ${ }^{1}$ Over a wide range of composition, there is virtually no change in the melting temperature of block copolyesters; however, comparable random copolymers showed greatly depressed melting temperatures. During the transformation of a pure homopolymer from the crystalline or partially crystalline state to the liquid state, there are characteristic changes in physical and mechanical properties, in morphology and structural features and in the thermodynamic variables. The thermodynamic definition of melting temperature, $T_{\mathrm{m}}(\mathrm{K})$, is given by the equation: $T_{\mathrm{m}}=\Delta H_{\mathrm{f}} / \Delta S_{\mathrm{f}}$ where $\Delta H_{\mathrm{f}}$ and $\Delta S_{\mathrm{f}}$ are the enthalpy and entropy of fusion respectively for the same amount of crystalline material in a polymer. ${ }^{2}$ The heat and entropies of fusion represent the differences in the enthalpy and entropy between the liquid and crystalline states. Unlike the low molecular weight crystalline substances, polymers melt over a wide range of temperature and it is customary to consider the higher temperature at which crystals disappear as the true melting temperature. ${ }^{3}$

Crystallization at a low temperature leads to the formation of a large number of small and imperfectly formed crystallites of correspondingly low melting temperatures, while at higher temperatures larger and more regular crystallites are formed with higher melting temperatures. ${ }^{3}$ When the sample was heated slowly,

\footnotetext{
${ }^{\dagger}$ Accepted for presentation at the 2nd SPSJ International Polymer Conference, Tokyo, Japan, August 18-21, 1986.

* Present address: Department of Physiology and Biophysics, University of Illinois, P.O. Box 6998, Chicago, Illinois 60680, U.S.A.

* To whom correspondences should be addressed.
} 
the smallest and least perfect crystallites melted first and took part in secondary recrystallization at a higher temperature, improving their degree of order and their size.

Very little has been reported concerning the degradation of copolyesters. ${ }^{4}$ The work by Carothers et al. $^{5}$ on polyesters was generally quoted as the standard reference for aliphatic polyester pyrolysis. $\mathrm{Phol}^{6}$ has studied the general trend of thermal degradation in polyesters by measuring the rate of total gas evolution, the change in coloration and the formation of acid end groups. These results indicated that (i) the polymer containing the repeat unit $\left(-\mathrm{CH}_{2}-\mathrm{CH}_{2}-\right)$ was the most stable and (ii) the introduction of a carboxyl group in the polymer chain increased the rate of degradation. This was attributed to the presence of a $-\mathrm{CH}_{2}-$ group adjacent to the oxygen, since the replacement of the $\beta$-hydrogen by methyl groups increased the stability.

Studies by Ritchie ${ }^{7}$ on the mechanism of thermal degradation of poly(ethylene terephthalate) (PET) using related model compounds established that the initial breakdown in the decomposition was primary alkyl-oxygen scission of the $\beta$-hydrogen type. While degradation of terephthalate acid/diethylene glycol polyester indicated ether linkages to be points of thermal stability. ${ }^{6}$ Marshall and Todd $^{8}$ studied the kinetics of degradation of PET in oxygen-free atmosphere and proposed a radical mechanism, since the rate of degradation was accelerated by oxygen. Rafler et al. ${ }^{9}$ studied the kinetics of thermal degradation of PET showed that the degradation rate was first order and evaluated the other kinetic parameter.

In the present study, the thermal properties of terephthalate copolyesters of ethylene glycol and butane-1,4-diol in varying compositions are described.

\section{EXPERIMENTAL METHODS}

The synthesis of the copolyesters are reported elsewhere. ${ }^{10}$

\section{Differential Thermal Analysis (DTA)}

A Mettler TA 2000 DTA system differential thermal analyzer was used to measure the melting temperature $\left(T_{\mathrm{m}}\right)$, crystallization temperature $\left(T_{\mathrm{c}}\right)$, etc. for the copolyesters. Samples of 5-10 $\mathrm{mg}$ of the powdered polymer were sealed in aluminium sample pan and crimped empty pan was used as reference and placed in the DTA cell. A heating rate of $10 \mathrm{~K} \mathrm{~min}^{-1}$ and chart speed of $1 \mathrm{~cm} \mathrm{~min} \mathrm{~m}^{-1}$ were used for all the heating and cooling operations. First the sample was heated to $10 \mathrm{~K}$ above the melting temperature and cooled to room temperature at the rate of $10 \mathrm{~K} \mathrm{~min}^{-1}$ to record the crystallization temperature. Melting and crystallization temperatures were determined by comparison with a calibration curve constructed by measuring the melting temperature of lead, tin, indium, benzoic acid, and naphthalene. For the purpose of these investigations, the melting temperature was defined as the temperature at which the DTA endotherm forms peak and the crystallization temperature was defined as the point at which the DTA curve forms an exothermic peak in the cooling cycle. The heats of transition corresponding to the endotherm or exotherm was determined by cutting out the area under the endothermic/exothermic peak and comparing it with the area of the standard indium transition using the following equation: ${ }^{11}$

$$
\Delta H_{\mathrm{f}}=A_{\mathrm{p}} / A_{\mathrm{i}} R_{\mathrm{p}} / R_{\mathrm{i}} S_{\mathrm{i}} / S_{\mathrm{p}} W_{\mathrm{i}} / W_{\mathrm{p}} \Delta H_{\mathrm{fi}}
$$

where

$\Delta H_{\mathrm{fi}}$ - the heat of fusion of indium $(6.8 \mathrm{cal}$ $\left.\mathrm{g}^{-1}\right)$,

$$
\begin{aligned}
& A_{\mathrm{p}} \text {-area of copolymer endotherm, } \\
& A_{\mathrm{i}} \text {-area of indium endotherm, } \\
& R_{\mathrm{p}} \text {-range setting used for copolymer DTA }
\end{aligned}
$$


curve,

$R_{\mathrm{i}}$-range setting used for indium DTA curve,

$S_{\mathrm{i}}$-chart speed used for indium DTA curve,

$S_{\mathrm{p}}$-chart speed used for copolymer DTA curve,

$W_{\mathrm{i}}$-weight in mg of indium sample taken, and

$W_{\mathrm{p}}$-weight in $\mathrm{mg}$ of copolymer sample taken.

Knowing $\Delta H_{\mathrm{f}}$ of the copolyesters (calculated from the above equation), the percent crystallinity $\left(X_{\mathrm{c}}\right)$, of the copolyesters were calculated by means of the following equation: ${ }^{12,13}$

$$
\begin{aligned}
\% X_{\mathrm{c}} & =\left[\Delta H_{\mathrm{f}}\left(E G \cdot M_{1}\right)+\left(B D \cdot M_{2}\right)\right] \\
& \times 100 / \Delta H_{\mathrm{f}}{ }^{0}\left(E G \cdot M_{1}\right)
\end{aligned}
$$

where

$E G-$ mole \% of ethylene terephthalate in the copolymer,

$M_{1}$-molecular weight of ethylene terephthalate repeat unit (192),

$B D-$ mole $\%$ of butylene terephthalate in the copolymer,

$M_{2}$ - molecular weight of butylene terephthalate repeat unit (220), and

$\Delta H_{\mathrm{f}}{ }^{0}$-heat of fusion per gram of repeat unit of PET (32.2 $\mathrm{cal} \mathrm{g}^{-1}$ ).

From the area of melting endotherm, the enthalpy of melting was calculated and hence the percent crystallinity.

\section{Thermogravimetry $(T G)$}

Thermal degradation of the copolyesters were studied by means of dynamic thermogravimetry with Stanton Redcroft TG-750 model thermobalance. $5 \mathrm{mg}$ of the sample was heated in nitrogen atmosphere at a heating rate of $10 \mathrm{~K} \mathrm{~min}^{-1}$. A platinum rhodium thermocouple was used to measure the temperatures. The primary TG curves were obtained by plotting the percent weight residue against temperature $\left({ }^{\circ} \mathrm{C}\right)$. Kinetic treatments are the same as published elsewhere. ${ }^{14-18}$

\section{RESULTS AND DISCUSSION}

When the copolyesters were heated in a DTA cell at a rate of $10 \mathrm{~K} \mathrm{~min}^{-1}$, it is found that a sharp endotherm occurred depending upon the comonomer content in the copolyesters (Table I, Figure 1). This endotherm is attributed to the melting of the copolyester. When the melt was cooled at a rate of $10 \mathrm{~K} \mathrm{~min}^{-1}$ from $10 \mathrm{~K}$ above the melting temperature to room temperature, a sharp exotherm occurred due to the crystallization of the polymers. The melting temperaturecomposition relations for these copolyesters follow an independent curve, so that an eutectic type minimum results at the intersection of the two curves ${ }^{19-21}$ (Figure 2). This is a typical character for random copolymers when studied over a wide range of compositions.

Table I shows the variations of thermodynamic parameters like melting temperature $\left(T_{\mathrm{m}}\right)$, crystallization temperature $\left(T_{\mathrm{c}}\right)$, enthalpy of fusion $\left(\Delta H_{\mathrm{f}}\right)$, entropy of fusion $\left(\Delta S_{\mathrm{f}}\right)$ and percent crystallinity $\left(X_{\mathrm{c}}\right)$ of copolyesters with $B D$ compositions. As the $B D$ content

\begin{tabular}{|c|c|c|c|c|c|c|}
\hline \multirow{2}{*}{ Polymer } & \multirow{2}{*}{ Mole $\%$ of $\mathrm{BD}$} & \multirow{2}{*}{$\frac{T_{\mathrm{m}}}{\mathrm{K}}$} & \multirow{2}{*}{$\frac{T_{\mathrm{c}}}{\mathrm{K}}$} & \multirow{2}{*}{$\frac{\Delta H_{\mathrm{f}}}{\mathrm{cal} \mathrm{g}^{-1}}$} & \multirow{2}{*}{$\frac{X_{\mathrm{c}}}{\%}$} & \multirow{2}{*}{ 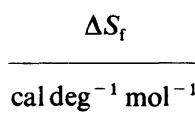 } \\
\hline & & & & & & \\
\hline P1 & 21.0 & 432.3 & 399.3 & 15.1 & 47.8 & 6.7 \\
\hline P2 & 28.2 & 428.8 & 397.8 & 14.1 & 45.3 & 6.3 \\
\hline P3 & 44.4 & 399.3 & 364.9 & 11.4 & 38.2 & 5.5 \\
\hline P4 & 48.7 & 404.8 & 375.8 & 9.2 & 31.9 & 4.4 \\
\hline
\end{tabular}

Table I. Effect of composition on the thermodynamic parameters of terephthalate copolyesters 


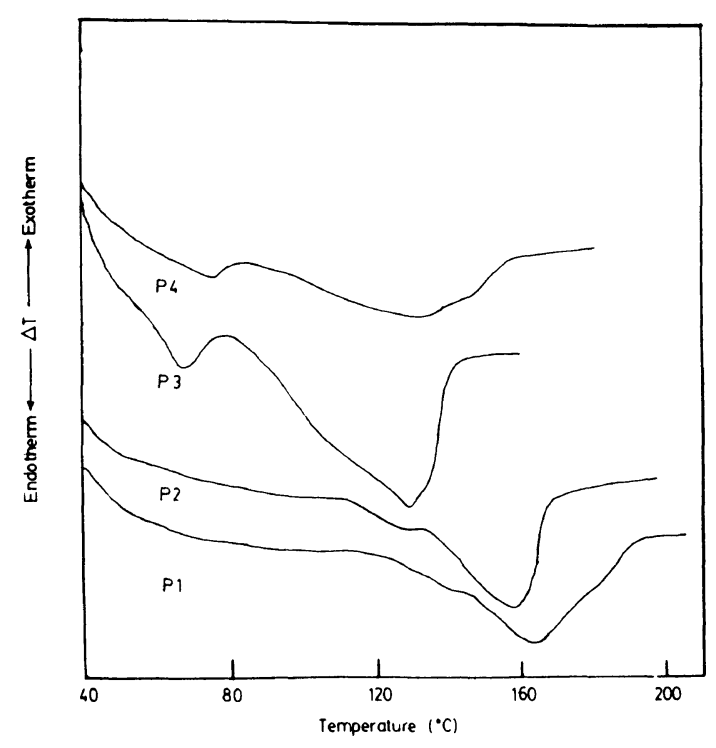

Figure 1. DTA curves for PET/BD Copolyesters.

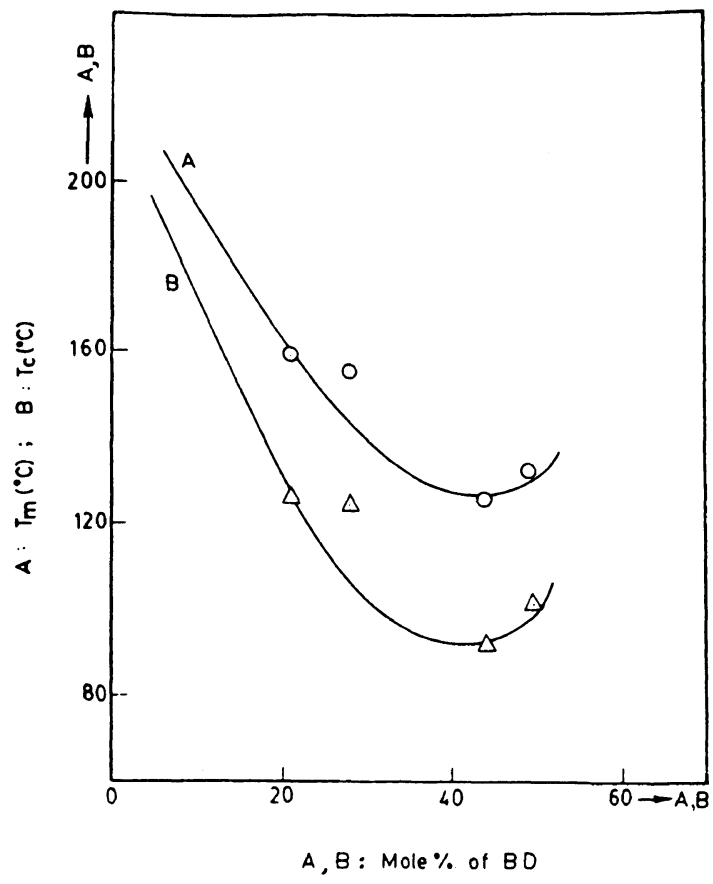

Figure 2. Variation of $T_{\mathrm{m}}$ and $T_{\mathrm{c}}$ with composition of PET/BD copolyesters.

increases in the copolyester, the $\Delta H_{\mathrm{f}}, \Delta S_{\mathrm{f}}$, and $X_{\mathrm{c}}$ decreases. This is due to the introduction of long alkyl chain $\left(-\mathrm{CH}_{2}-\mathrm{CH}_{2}-\mathrm{CH}_{2}-\mathrm{CH}_{2}-\right)$ in the backbone structure. The melting temperature of a crystalline polymer depends on a number of intra- and intermolecular structural characteristics of the repeating units, the most


regularity, (b) bond flexibility, (c) close packing ability, and (d) interchain attraction. High melting temperatures are generally associated with either highly regular structures or rigid molecular structures, or capability of close packing of polymer chains or strong interchain attraction or a combination of these factors.

Multiple melting phenomena are observed for all the copolyesters (Figure 1). The phenomena of double peaked fusion curves were reported by Kamide et al. ${ }^{26}$ for highly isotactic unfractionated polypropylene. The multiple melting behavior of tetramethylene terephthalate-tetramethylene sebacate and dimethyl terephthalate-ethylene glycol-butane1,4-diol copolyesters were observed. ${ }^{27}$ The lower temperature peak was assigned to the melting of crystals originally present in the polymer whereas the higher melting peak was due to the melting of crystallites formed from the polymer melt.

The decrease in $T_{\mathrm{m}}$ with increasing amount of $B D$ content in the copolymer is in good agreement with the theory of equilibrium melting of random copolymers. ${ }^{28}$ This theory predicts a depression in melting temperature caused by the noncrystallizing units according to Flory's equation ${ }^{28}$ :

$$
1 / T_{\mathrm{m}}-1 / T_{\mathrm{m}}{ }^{0}=-R / \Delta H_{\mathrm{f}} \cdot \ln X_{\mathrm{A}}
$$

where $T_{\mathrm{m}}$, the melting temperature of the copolymer; $T_{\mathrm{m}}{ }^{0}$, the melting temperature of the homopolymer; $\Delta H_{\mathrm{f}}$, the enthalpy of fusion per repeat unit of homopolymer; $R$, the gas constant; and $X_{\mathrm{A}}$, the mole fraction of crystallizable units. The melting temperature depression is dependent on the heat of fusion per mol of the crystallizing unit and on the sequence propagation probability, $p$, which is $X_{\mathrm{A}}$ for random copolymers. ${ }^{28}$ From the slope of a plot of $T_{\mathrm{m}} v s$. $X_{\mathrm{A}}$ of PET (Figure 3), the 




Figure 3. Melting temperatures and composition relationship for the copolyesters of PET (Flory's equation verification).

value of $2.650 \mathrm{kcal}$ per mol is obtained for the heat of fusion of PET which is significantly lower than the value of $5.837 \mathrm{kcal}$ per mol reported by Smith and Dole. ${ }^{29}$ The values of $\Delta H_{\mathrm{f}}$ determined from an analysis of copolymer melting always differ by varying amounts from the values obtained by other methods. ${ }^{30}$ There is an apparent discrepancy which resides in either the experimental methods or the subsequent analysis. From the DTA studies, the $\Delta H_{\mathrm{f}}$ is found to be $2.275 \mathrm{kcal}$ per mol for PET. This is lower than that predicted by Flory's equation $(2.650 \mathrm{kcal}$ per mol$)$.

Using Flory's equation, the $T_{\mathrm{m}}{ }^{0}$ calculated is in quite agreement with the $T_{\mathrm{m}}$ of PET obtained by DTA method. $T_{\mathrm{m}}{ }^{0}$ calculated for PET by Flory's equation is $518 \mathrm{~K}$. The value obtained by DTA method for PET is found to be $519 \mathrm{~K}$. The melting temperature defined by Flory's equation is that temperature at which perfect crystallites composed of extremely long sequences of ' $A$ ' uits become unstable. It has been shown that the number of crystallites melting will be extremely small. ${ }^{31,32}$ Thus, despite the use of very sensitive detectors of crystallinity, the observed melting temperatures are caused by the disappearance of crystallites composed of shorter sequences. Also the noncrystallizable units impose restraint on the crystallization of PET units with result that the majority of PET units could not crystallize. As a result there is a large decrease in the $T_{\mathrm{m}}$ values and the difference between the theoretical and observed values of $T_{\mathrm{m}}$ is widespread among the copolymers. ${ }^{33}$

The melting temperature was shown to depend only on the composition and were independent of the chemical nature of coingredient that is introduced in the copolymers of PET and poly(hexamethylene adipamide). ${ }^{30} \mathrm{By}$ wide angle $\mathrm{X}$-ray studies, it has been shown that only one of the units participates in the crystallization. This is in accordance with the random distribution of sequences in the copolymer. $^{30}$

Table I shows that the $\Delta H_{\mathrm{f}}$ value decreases as the concentration of the coingredient is increased. It decreases with composition in a regular fashion. ${ }^{34}$ The percent crystallinity and the $\Delta S_{\mathrm{f}}$ values of the copolyester also follow the above mentioned trend. The $\Delta S_{\mathrm{f}}$ values of PET and PBT reported in the present study are 4.4 and $7.7 \mathrm{cal}$ per degree per mol, respectively which is in good agreement with the values obtained by Conix and Van Kerpel ${ }^{35}$ by the polymer diluent method. The $\Delta S_{\mathrm{f}}$ values of the copolyesters are in between the homopolyesters (PET and PBT). From the $X_{\mathrm{c}}$ values, it is obvious that the crystallinity is decreased due to the incorporation of another comonomer into the polymer. Lenz et al. ${ }^{36}$ reported a $\Delta H_{\mathrm{f}}$ value of $8.61 \mathrm{cal}$ per gram for $50 \%$ $E G / 50 \% B D$ terephthalate copolyester which is in good agreement with the value reported by the authors, $9.2 \mathrm{cal}$ per gram for $51.3 \%$ $E G / 48.7 \% B D$ copolyester.

\section{Thermogravimetry}

The TG trace for P2 and P4 copolyesters are 
Table II. Activation energies for the degradation of terephthalate homo- and copolyesters of ethylene glycol and butane-1,4-diol according to different methods of evaluation

\begin{tabular}{|c|c|c|c|c|c|}
\hline \multirow{3}{*}{ Polymer } & \multirow{3}{*}{$\begin{array}{c}\begin{array}{c}\text { Temperature } \\
\text { range }\end{array} \\
\mathrm{K}\end{array}$} & \multirow{3}{*}{$\begin{array}{c}\text { Total weight } \\
\text { loss } \\
\%\end{array}$} & \multicolumn{3}{|c|}{ Energy of activation } \\
\hline & & & \multicolumn{3}{|c|}{$\mathrm{kcal} \mathrm{mol}^{-1 \mathrm{a}}$} \\
\hline & & & Coats and redfern ${ }^{14}$ & Doyle $^{15}$ & Murray and White ${ }^{16}$ \\
\hline PET & $584-721$ & 93.5 & 33.0 & 35.7 & 39.0 \\
\hline $\mathbf{P} 2$ & $472-721$ & 93.6 & 25.1 & 27.9 & 31.0 \\
\hline P3 & $346-702$ & 94.0 & 9.2 & 10.1 & 7.4 \\
\hline P4 & $308-730$ & 88.7 & 12.6 & 13.1 & 18.0 \\
\hline $\mathrm{PBT}^{\mathrm{b}}$ & $558-693$ & 99.7 & 39.0 & 40.7 & 48.0 \\
\hline
\end{tabular}

a In SI units $1 \mathrm{cal}=4.184 \mathrm{~J}$.

b PBT, poly(butylene terephthalate).



Figure 4. Thermogravimetric curves for PET/BD copolyesters P2 (curve A) and P4 (curve B) (cf. Table I).

given in Figure 4. The degradation reaction was carried out in nitrogen atmosphere. Decomposition occurs for PET at $584 \mathrm{~K}$; for $\mathrm{P} 2,472 \mathrm{~K}$; for P3, 346 K; for P4, 308 K; and for PBT, $558 \mathrm{~K}$ (Table II). The major decomposition takes place in the range $573-730 \mathrm{~K}$ for all homo- and copolyesters. The wide variation in the starting decomposition temperature for these copolyesters is due to the change in microstructure of the copolyester, that is, as the $B D$ content is increased in PET, the polyester-ether formation ${ }^{37,38}$ is also increased and hence the lower temperature of degradation results. ${ }^{6}$ A weight loss of 10 $20 \%$ for P2, P3 and P4 copolyesters is attributed to the polyether degradation depending upon the composition of $B D$ in the copolyester (Figure 4). After this degradation, the TG trace follow a regular trend in the order of reaction, that is, first order degradation.

The activation energies for the homo- and copolyesters have been calculated using three different approximation methods. ${ }^{14-16}$ Figure 5 shows the calculation of activation energy for P2 copolyester using three different methods. The activation energy for the degradation of copolyesters follows an eutectic type minimum with composition, like $T_{\mathrm{m}}, T_{\mathrm{c}}$, etc. The activation energies calculated from various approximate methods are given in Table II and are in good agreement with each other within the experimental error except Murray and White method. ${ }^{16}$

The thermal stability of the homo- and copolyesters are listed in Table III. All these polymers degrade more than $95 \%$ weight around $773 \mathrm{~K}$ without leaving any residue. The activation energy for PBT is found to be $\sim 40 \mathrm{kcal}$ per mol and it is in good agreement with the value $(41 \mathrm{kcal}$ per mol) reported by 


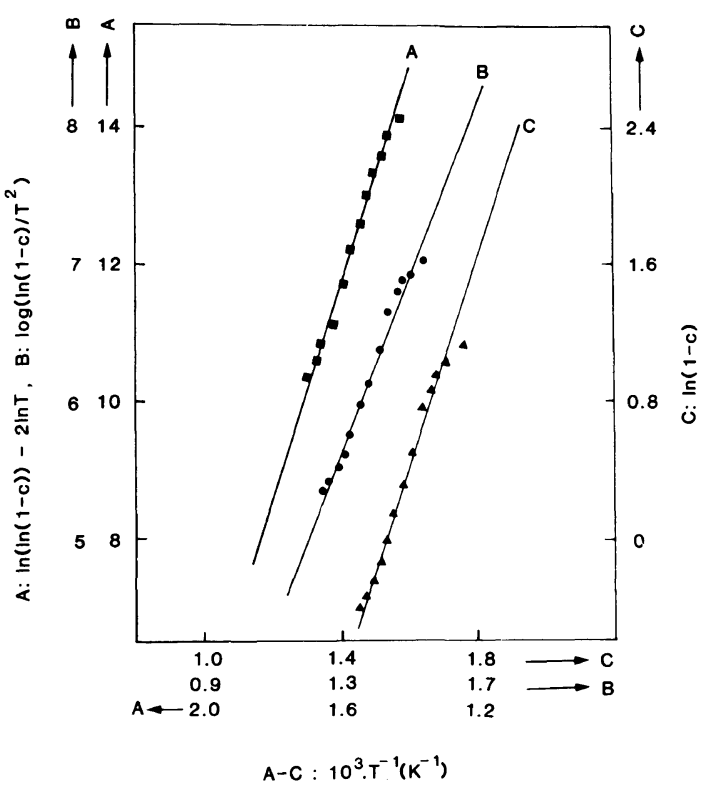

Figure 5. Calculation of activation energies for the degradation of copolyester P2 (cf. Table I) according to Murray and White ${ }^{16}$ (plot A), Coats and Redfern ${ }^{14}$ (plot B), and Doyle ${ }^{15}$ (plot C).

Table III. Thermal stability of the homoand copolyesters

\begin{tabular}{lllll}
\hline & \multicolumn{4}{c}{ Temperature at specific percentage } \\
weight loss/K
\end{tabular}

Passalacque et al. ${ }^{39}$ The activation energy for PET, calculated by authors is $\sim 35 \mathrm{kcal}$ per mol. It was postulated that the scission of the ester group to olefin and carboxylic groups was the primary degradation reaction for PET ${ }^{40,41}$ Since the copolyesters studied have $\beta$-hydrogen atoms in the diol portion, the classical cyclic mechanism observed for the decomposition of simple esters is applicable.

Acknowledgement. The authors wish to thank Dr. C. T. Vijayakumar for DTA analysis. One of the authors (E.P.) acknowledges the University Grants Commission, New Delhi for the financial support.

\section{REFERENCES}

1. G. A. Clegg, D. R. Gee, and T. P. Melia, Makromol. Chem., 120, 210 (1968).

2. L. Mandelkern, "Crystallization of Polymers," McGraw-Hill, New York, N.Y., 1964, Chapter 4.

3. R. D. Evans, H. R. Mighton, and P. J. Flory, J. Am. Chem. Soc., 72, 2018 (1950).

4. R. T. Conley, "Thermal Stability of Polymers, Monographs in Macromolecular Chemistry-," Vol. 1, Marcel Dekker Inc., New York, N.Y., 1970, p 401.

5. H. Mark and R. Whitby, Ed., Collected papers of W. H. Carothers on Polymerization, "High Polymers," Vol. I, Wiley Interscience, New York, N.Y., 1940.

6. H. A. Pohl, J. Am. Chem. Soc., 73, 5660 (1951).

7. P. D. Ritchie, in the Socoiety of Chemical Industry Monograph No. 13, London, 1961, p 107.

8. I. Marshall and A. Todd, Trans. Faraday Soc., 49, 67 (1963).

9. G. Rafler, J. Blaesche, H. Gajewski, and K. Zacharias, Acta Polym., 31, 633 (1980).

10. T. Balakrishnan, E. Ponnusamy, and $\mathrm{H}$. Kothandaraman, Polym. Bull., 5, 187 (1981).

11. R. P. Sheldon, Polymer, 3, 213 (1962).

12. G. Challa, Makromol. Chem., 38, 123 (1960).

13. R. W. Lenz and A. N. Schuler, J. Polym. Sci., Polym. Symp., 63, 343 (1978).

14. A. W. Coats and J. P. Redfern, Nature (London), 201, 68 (1964).

15. C. D. Doyle, J. Appl. Polym. Sci., 6, 639 (1962).

16. P. Murray and J. White, Trans. Br., Ceram. Soc., 54, 151 (1955).

17. E. Ponnusamy, T. Balakrishnan, and $\mathrm{H}$. Kothandaraman, Makromol. Chem., 184, 1279 (1983).

18. E. Ponnusamy and T. Balakrishnan, Polym. J., 17, 473 (1985).

19. O. B. Edgar and E. Ellery, J. Chem. Soc., 2633 (1952).

20. S. Sonnerskog, Acta Chem. Scand., 10, 113 (1956).

21. E. F. Izard, J. Polym. Sci., 8, 503 (1952).

22. R. W. Lenz, "Organic Chemistry of Synthetic High Polymers," Interscience Publishers, New York, N.Y., 1967, p 91.

23. R. E. Wilfong, J. Polym. Sci., 54, 383 (1961).

24. D. G. Bannerman and E. E. Magat, in "Polymer Processes," C. E. Schildknecht Ed., Interscience, New York, N.Y., 1956, p 146.

25. R. J. W. Reynolds, in "Fibers from Synthetic Polymers," R. H. Hill Ed., Elsevier, Amsterdam, 1953, p 146. 


\section{E. Ponnusamy and T. Balakrishnan}

26. K. Kamide and K. Yamaguchi, Makromol. Chem., 162, 205 (1972).

27. W. Marrs, R. H. Peters, and R. H. Still, J. Appl. Polym. Sci., 23, 1077 (1979); C. T. Vijayakumar, E. Ponnusamy, T. Balakrishnan, and $\mathrm{H}$. Kothandaraman, J. Polym. Sci., Polym. Chem. Ed., 20, 2715 (1982).

28. P. J. Flory, Trans. Faraday Soc., 51, 848 (1955).

29. C. W. Smith and M. Dole, J. Polym. Sci., 20, 37 (1956).

30. L. Mandelkern, "Crystallization of Polymers," McGraw-Hill, New York, N.Y., 1964.

31. L. Mandelkern, M. Tryon, and F. A. Quinn, J. Polym. Sci., 19, 77 (1956).

32. M. Dole and B. Wunderlich, Makromol. Chem., 34, 29 (1959).

33. L. Mandelkern, Rubber Chem. Technol., 32, 1392 (1959).

34. W. J. Jackson, Jr. and H. F. Kuhfuss, J. Polym. Sci.,
Polym. Chem. Ed., 14, 2043 (1976); E. Ponnusamy, C. T. Vijayakumar, T. Balakrishnan, and $\mathrm{H}$. Kothandaraman, Polymer, 23, 1391 (1982).

35. A. Conix and R. Van Kerpel, J. Polym. Sci., 40, 521 (1959).

36. G. Galli, E. Benedetti, E. Chiellini, C. Ober, and R. W. Lenz, Polym. Bull., 5, 497 (1981).

37. E. Ponnusamy, T. Balakrishnan, and $\mathrm{H}$. Kothandaraman, Proceedings of the 27th IUPAC Macromolecular Symposium, Strasbourg, France, 1981, Vol. 1, p 32.

38. S. Fakirov, I. Seganov, and E. Kurdowa, Makromol. Chem., 182, 185 (1981).

39. V. Passalacqua, F. Pilati, V. Zamboni, B. Fortunato, and P. Manaresi, Polymer, 17, 1044 (1976).

40. P. D. Ritchie, in the Society of Chemical Industry Monography No. 13, London, 1961, p 107.

41. E. P. Goodongs, in the Society of Chemical Industry Monograph No. 13, London, 1961, p 211. 